\title{
Dynamic measurement of complex phenomena in assessing the Europe 2020 strategy effects
}

Iwona Müller-Frączek

Nicolaus Copernicus University

in Toruń

Faculty of Economic Sciences and

Management, Poland

E-mail: muller@econ.umk.pl

Keywords: multidimensional data analysis, composite indicator, normalization
The paper presents a novel construction of dynamic composite indicators modelled on the Human Development Index (HDI), where, instead of scaling, the author applies normalization with respect to anti-pattern: an original method of variable normalization. This method enables the reflection of different environments (reference groups) in dynamic synthetic comparative studies. An empirical example illustrates the utility of the new method. As regards the Europe 2020 strategy, the socio-economic development of 10 countries that joined the European Union (EU) in 2004 is analysed from the perspective of this group of countries as well as the whole EU. The results for the two groups (environments) are similar, but not identical. The study finally carries out an in-depth analysis for the selected country, Poland. Again, both environments show visible differences.

\section{Introduction}

International or regional comparisons often adopt a synthetic approach. This approach combines different aspects of the studied complex (multidimensional) phenomenon into one quantitative characteristic, the so-called composite indicator (or composite index, a synthetic variable). This synthetic comparative research has advantages and disadvantages (Saltelli 2007), but is popular both in science and journalism owing to the simplicity of its interpretation. For a complex phenomenon, many different examples of composite indicators can be found in the literature. For example, the history of creating various composite indicators for the socioeconomic development of countries is described in Booysen (2002). Some researchers create their own composite indicators (e.g. Müller-Frączek-Muszyńska 2016, Valkó et al. 2017), but many scientists use already existing ones (Egri-Tánczos 2018, among others).

The creation of composite indicators should be carried out with due diligence. The rules to be followed and stages of construction are presented in the literature; for example, see Zeliaś (2002), Saisana-Saltelli (2011), Casadio Tarabusi-Guarini (2013), and Mazziotta-Pareto (2013). 
From the viewpoint of this article, the composite indicators need to be divided into static and dynamic ones. Static composite indicators characterize the phenomenon for a specific unit of time. They can be used for analysis across time, but then we can only compare rankings and not the index values. However, dynamic composite indicators characterize the phenomenon for various time units so that the rankings as well as the index values can be compared.

This article focuses on dynamic composite indicators. A key issue in the construction of dynamic composite indicators is making the variables comparable, that is, normalizing the diagnostic variables (individual indicators). For examples of normalization formulas, see Milligan-Cooper (1988), Jajuga-Walesiak (2000), and Młodak (2006).

Two approaches are used for dynamic normalization. In the first one, all the available observations of an individual variable (in both time and space) are used to determine the parameters needed for normalization (Nardo et al. 2005). The disadvantage of this solution is that once a new unit of time is observed, all the results will have to be recalculated. In the second approach, the parameters needed for normalization are set in advance and also for the future. This solves the problem of recalculating the results but makes it difficult to define the mentioned parameters, especially when very diverse objects are analysed (for some methods, see MazziottaPareto 2016).

This study applies a different approach to dynamic normalization than the ones mentioned above. Indicators are statically transformed, i.e. for each unit of time separately, nonetheless their normalized values are comparable not only in space but also over time. This procedure is generally not applied, but for the author's method of normalization (called normalization with respect to anti-pattern, or anti-pattern normalization in short), it is correct.

The aim of this article is to present a new method for dynamic composite indicators construction using anti-pattern normalization. A prototype of this method is normalization with respect to pattern, which has been also used by Müller-Frączek (2018) for composite indicators construction. Anti-pattern normalization is used for the first time in this study.

Normalization with respect to anti-pattern is adapted for dynamic studies, but unlike popular methods, it uses observations from only the current time unit (a static approach). Therefore, the composite indicators based on this method do not require the results to be recalculated after the appearance of observations for a new time unit.

To analyse a complex phenomenon, we often assess the situation of the object (country, region) against the background of different reference groups (environments). Depending on the normalization method we choose for constructing the composite indicator, the reference group may or may not influence the synthetic results. During anti-pattern normalization, observations for all objects are used,

Regional Statistics, Vol. 9. No. 1. 2019: 32-53; DOI: 10.15196/RS090107 
therefore the research environment is really important for constructions based on this method. The normalization results obtained are relative, and the results for another reference group can be very much different.

Note, importantly, that not all dynamic synthetic analyses can be conducted using the proposed composite indicator. Studied complex phenomena should consist of several aspects that are not substitutable with one another. However, each of these aspects can be represented by several mutually substitutable indicators. In addition, the results obtained using the proposed method strongly depend on the analysis environment. They reflect not the objective changes in indicators, but the changes in terms of the analysed reference group. It is worth confronting them with research based on other methods of normalization. Then the image of the studied phenomenon will be more complete.

To illustrate the utility of the proposed method, we analyse the countries in terms of implementation of the Europe 2020 strategy, a program of socio-economic development of the EU countries for 2010-2020 with the following priorities:

- smart development,

- sustainable development,

- inclusive development.

The appropriate indicators to monitor the implementation of the strategy are determined. They are published in the Eurostat database. For more information on the strategy, see the official website of the European Commission.

In this study, we present a dynamic synthetic analysis of the EU countries' development in the context of the Europe 2020 strategy, with focus on 10 countries that joined the EU in 2004 (this group is referred to as the EU10 countries in this article). The development level of the individual countries is assessed from the perspectives of two groups: the EU10 countries and the whole EU. The results obtained for these reference groups are then compared.

To highlight the difference in the results for the different environments, we carry out an in-depth analysis of one country, Poland. ${ }^{1}$ Note that we discuss not the development of this country, but the difference between the results obtained for the different environments.

The remainder of the article is structured as follows. Section 2 presents the construction of the dynamic composite indicator. Section 3 describes our empirical study. Section 4 presents the synthetic analysis results of the EU10 countries' development. Section 5 compares the analysis results obtained for the two environments. Section 6 presents an in-depth analysis for Poland. The article ends with conclusions.

\footnotetext{
${ }^{1}$ The described results were presented at the V. International Scientific Conference 'Spatial Econometrics and Regional Economic Analysis' in Łódź (Poland). Therefore, we selected Poland as our example.
}

Regional Statistics, Vol. 9. No. 1. 2019: 32-53; DOI: 10.15196/RS090107 


\section{Construction of the dynamic composite indicator}

An aggregation of the variables used for the presented construction is modelled on the HDI, a composite indicator used by the United Nations for dynamic comparison of countries around the world in terms of the level of socio-economic development (for more information on HDI, see the official website of the United Nations Development Programme).

In the first step of the construction, we normalize the individual variables (indicators). ${ }^{2}$ Next, we divide them into groups, corresponding to the different aspects of the multidimensional phenomenon. We assume more than one variable in each group. We also assume that the variables connected with an aspect are substitutable; that is, the surplus in one indicator can compensate for a deficit in another. Thus, we use a compensatory method of aggregation within groups (the arithmetic mean). ${ }^{3}$ However, since the different aspects of the phenomenon are assumed to be nonsubstitutable, we integrate all aspects into one combined composite indicator using a method that hinders compensation between the aspects (the geometric mean). ${ }^{4}$

The difference between the construction of the HDI and that of the composite indicator proposed in this article is due to the use of different method of variable normalization. As mentioned in Section 1, the presented construction method uses normalization with respect to anti-pattern, whereas the HDI uses scaling min-max normalization or zero unitarization in the version adopted for dynamic analysis.

Let $n \in N$ be the number of considered objects (regions, countries, etc.) and $x=\left(x^{1}, x^{2}, \ldots, x^{n}\right) \in R^{n}$ be a selected diagnostic variable characterising a complex phenomenon (e.g. socio-economic development) in a fixed time unit, for simplicity of notation. For each object $i=1, \ldots, n$; the scaling used in HDI transforms variable $x$ into variable $s=\left(s^{1}, s^{2}, \ldots, s^{n}\right) \in \mathrm{R}^{n}$ as follows: ${ }^{5}$

$$
s^{i}=\frac{x^{i}-x^{\min }}{x^{\max }-x^{\min }} \quad \text { if } \quad x \in S
$$

In a basic (static) version of the scaling $x^{\min }$ and $x^{\max }$ are the maximum and minimum among the values of the variable $x$ for a given time unit. In a dynamic approach, however, the maximum and minimum among values for all objects and all time units are selected. As mentioned in Section 1, the disadvantage of this method is that all the previous results have to be recalculated when the observations for a new year appear. Therefore, in the HDI, $x^{\min }$ and $x^{\max }$ do not result directly from

\footnotetext{
2 The problem of variable selection is beyond the scope of this article.

${ }^{3}$ For more information on substitution in variable aggregation methods, see, for example, Klugman et al. (2011).

${ }^{4}$ For simplicity of presentation, we also assume that all features in each group are equally important and skip the weighting variables step.

${ }^{5}$ Formula (1) is given for stimulants because HDI contains only stimulants. For a general form and other details of this normalization method, see, for example, Kukuła-Bogocz (2014).
}

Regional Statistics, Vol. 9. No. 1. 2019: 32-53; DOI: 10.15196/RS090107 
the distribution of the variable but are predetermined values ('goalposts') common for all countries and all (also future) years of analysis (Tarantola 2008).

In practice, it is difficult to determine the values of $x^{\min }$ and $x^{\max }$ that are adequate for all countries in the long term, because, first, the countries of the world are very diverse in terms of socio-economic development level, and, second, the values of the indicators used in the HDI are growing in time. The developed countries have already exceeded the maximum level of some of the indicators used in the HDI.

In the context of this study, scaling has one more disadvantage: the value of $s$ for a given country is not influenced by those of other countries, and so the environment of the research is not relevant. Normalization with respect to anti-pattern does not have this disadvantage.

The indicators forming the HDI are stimulants, that is, diagnostic variables, which have a positive impact on socio-economic development. In general, a set of diagnostic variables can also include destimulants, which have a negative impact on the studied phenomenon. To use all the diagnostic variables in the construction of a composite indicator, the destimulants should be converted into stimulants. Such a possibility is given by normalization with respect to anti-pattern, which is another advantage of this method.

In the first step of normalization, we define the anti-pattern for variable $x=\left(x^{1}, x^{2}, \ldots, x^{n}\right) \hat{\mathrm{I}} \mathrm{R}^{n}$ as follows:

$$
x^{\mathrm{ant}}=\left\{\begin{array}{lll}
\min _{i} x^{i} & \text { if } & x \in S, \\
\max _{i} x^{i} & \text { if } & x \in D,
\end{array}\right.
$$

where $S$ and $D$ are sets of stimulants and destimulants, respectively.

After specifying the anti-pattern, we consider a new variable, $u=\left(u^{1}, u^{2}, \ldots, u^{n}\right)$, instead of variable $x$, given by

$$
u^{i}=\frac{\left|x^{i}-x^{\mathrm{ant}}\right|}{\sum_{j=1}^{n}\left|x^{j}-x^{\mathrm{ant}}\right|}=\left\{\begin{array}{lll}
\frac{\left(x^{i}-x^{\mathrm{ant}}\right)}{\sum_{j=1}^{n}\left(x^{j}-x^{\mathrm{ant}}\right)} & \text { if } & x \in S, \\
\frac{\left(x^{\mathrm{ant}}-x^{i}\right)}{\sum_{j=1}^{n}\left(x^{\mathrm{ant}}-x^{j}\right)} & \text { if } & x \in D .
\end{array}\right.
$$

A normalized variable $u$ has a clear interpretation. $u^{i}$ specifies the share of distance between the $i$-th object and anti-pattern in the total distance of all objects from the anti-pattern. The $i$-th object is in a better situation when the value of $u^{i}$ is higher. Therefore, the variable after normalization becomes a stimulant, regardless of its initial character. Other properties of anti-pattern normalization are presented below.

- Arithmetic mean:

$$
\bar{u}=\frac{1}{n} \text {. }
$$

Regional Statistics, Vol. 9. No. 1. 2019: 32-53; DOI: 10.15196/RS090107 
- Standard deviation:

$$
S(u)=\left\{\begin{array}{lll}
\frac{\mathrm{S}(x)}{n\left(\bar{x}-x^{\mathrm{ant}}\right)} & \text { if } & x \in S, \\
\frac{\mathrm{S}(x)}{n\left(x^{\mathrm{ant}}-\bar{x}\right)} & \text { if } & x \in D .
\end{array}\right.
$$

- Skewness:

$$
\mathrm{A}(u)=\left\{\begin{array}{rrr}
\mathrm{A}(x) & \text { if } & x \in S \\
-\mathrm{A}(x) & \text { if } & x \in D .
\end{array}\right.
$$

- Kurtosis:

$$
\mathrm{K}(u)=\mathrm{K}(x) \text {. }
$$

- Pearson correlation coefficient:

$$
\rho\left(u_{1}, u_{2}\right)=\left\{\begin{aligned}
\rho\left(x_{1}, x_{2}\right) & \text { if } x_{1}, x_{2} \in S \text { or } x_{1}, x_{2} \in D, \\
-\rho\left(x_{1}, x_{2}\right) & \text { otherwise }
\end{aligned}\right.
$$

The environmental context is often important in comparative studies. It is helpful to have a tool to consider this context. During scaling in version (1), the situation of other countries does not affect the value of $s$ for a given country. This is not the case for normalization with respect to anti-pattern. The values of variable $u$ reflect the situation of a country against the background of the whole environment. This is similar as for other forms of normalization, such as standardization, but the environment is specified in a different way. In anti-pattern normalization, the environment is represented by the sum of the distances between the objects and antipattern, whereas in common normalizations, the descriptive characteristics of the distribution of $x$ are used for this purpose. ${ }^{6}$

The most important advantage of anti-pattern normalization is the comparability of variables in space as well as over time. If for the $i$-th country, the value of a normalized feature increases in time, it means that this country moves relatively away from the worst country such that its situation in the given environment improves. Thus, after a static anti-pattern normalization, the features are 'naturally' comparable over time. Therefore, this method is useful for dynamic studies, although only the observations from a current unit of time are used during normalization. Unlike for dynamic standardization, you do not have to recalculate all the results when you obtain new data for the next year.

${ }^{6}$ Because normalization is not the main topic of the article, we do not compare anti-pattern normalization with the other methods. However, note that many normalization methods exist, and in some of them, the values for other objects have an impact on the normalized value of a given object; for some newer cases, see for example, Lira et al. (2002) and Młodak (2006, 2014).

Regional Statistics, Vol. 9. No. 1. 2019: 32-53; DOI: 10.15196/RS090107 


\section{Description of empirical study}

The empirical study illustrates the method of constructing the composite indicators described in Section 2. It highlights the differences in the results obtained for different reference groups. ${ }^{7}$

The relative socio-economic development of the EU10 countries is examined in the context of the Europe 2020 strategy. The development of individual countries is analysed against the background of other group members and the entire EU. An empirical study is conducted for the period 2010-2015. The data are taken from the statistical office of Poland (Statistics Poland 2018). All 11 indicators, that is, four stimulants and seven destimulants monitoring the implementation of the Europe 2020 strategy are used. ${ }^{8}$ The indicators characterize the aspects of socioeconomic development important from the viewpoint of the strategy. ${ }^{9}$ For the study, they are assigned to the respective strategy priorities.

Group 1. Smart development:

$x_{1}-$ Gross domestic expenditure on R\&D ( $\%$ of GDP; $x_{1} \in \mathrm{S}$ ),

$x_{2}$ - Early leavers from education and training $\left(\% ; x_{2} \in \mathrm{D}\right)$,

$x_{3}-$ Tertiary educational attainment of persons aged $30-34\left(\% ; x_{3} \in \mathrm{S}\right)$.

Group 2. Sustainable development:

$x_{4}-$ Greenhouse gas emissions $\left(1990=100 ; x_{4} \in \mathrm{D}\right)$,

$x_{5}$ - Share of renewables in gross final energy consumption $\left(\% ; x_{5} \in \mathrm{S}\right)$,

$x_{6}-$ Consumption of primary energy (kgoe per 1,000 EUR; $x_{6} \in \mathrm{D}$ ).

Group 3. Inclusive development:

$x_{7}$ - Employment rate of persons aged 20-64 $\left(\% ; x_{7} \in \mathrm{S}\right)$,

$x_{8}$ - Share of people at risk-of-poverty or social exclusion $\left(\% ; x_{8} \in \mathrm{D}\right)$,

$x_{9}$ - People living in households with very low work intensity $(\%$; $\left.x_{9} \in \mathrm{D}\right)$,

$x_{10}$ - People at risk-of-poverty rate (after social transfers) $\left(\% ; x_{10} \in \mathrm{D}\right)$,

$x_{11}$ - Severely materially deprived people $\left(\% ; x_{11} \in \mathrm{D}\right)$.

Based on the listed indicators, the development of the EU10 countries is examined, applying the methods described in Section 2.10 The two approaches used for the normalization of variables allow for assessing the phenomenon from different

\footnotetext{
${ }^{7}$ For this purpose, the prototype of the proposed method, HDI, cannot be used, because some aspects of this index are characterized by only one indicator.

8 The strategy sets targets for all indicators that should be implemented by individual countries as well as the entire EU. Therefore, none of the indicators can be omitted in the construction of a composite indicator.

9 The presented results may differ significantly from other studies on socio-economic development of the EU owing to the use of specific indicators (Fura-Wang 2017).

${ }^{10}$ Because of this specific method of normalization, the results obtained are relative. Therefore, it is worth confronting them with results obtained on the basis of other types of normalization. However, this is beyond the scope of this article.
}

Regional Statistics, Vol. 9. No. 1. 2019: 32-53; DOI: 10.15196/RS090107 
perspectives. The first approach considers only the environment of the EU10 countries, whereas the second approach takes all the EU countries (hereinafter EU28) into account.

Anti-pattern normalization results in 11 stimulants. They are labelled as $u_{1}$, $u_{2}, \ldots, u_{1}$, respectively. Then the variables inside each group are aggregated using the arithmetic mean. ${ }^{11}$ Thus, we obtain the following:

- a composite indicator of smart development

$$
I_{1}=\frac{u_{1}+u_{2}+u_{3}}{3}
$$

- a composite indicator of sustainable development

$$
I_{2}=\frac{u_{4}+u_{5}+u_{6}}{3}
$$

- a composite indicator of inclusive development

$$
I_{3}=\frac{u_{7}+u_{8}+u_{9}+u_{10}+u_{11}}{5} .
$$

Next, the composite indicators for individual groups are aggregated using the geometric mean. Thus, we obtain the following composite indicator of socioeconomic development:

$$
I=\sqrt[3]{I_{1} \cdot I_{2} \cdot I_{3}} .
$$

This indicator synthetically characterizes the countries in terms of aspects relevant to the strategy.

Two versions of the composite indicators $I_{1}, I_{2}, I_{3}$, and $I$ are created. They correspond to the different environments of the study. In one group, the EU10 countries are characterized against their own background, whereas in the other, we look at them from the perspective of the entire EU.

\section{Empirical results}

The results of the study described in Section 3 are shown in Appendix Tables 1-5. Table 1 presents the values of indicators monitoring the implementation of the strategy for Poland and the position of Poland in the EU10 countries based on a given indicator. Three versions of the indicator values are presented:

- before normalization,

- after anti-pattern normalization in the EU10 environment,

- after anti-pattern normalization in the EU28 environment.

The results for the other EU10 countries are not presented; however, 2015 showed an improvement in almost all raw indicators (the exception was $x_{10} \in \mathrm{D}$ ) in most of the EU10 countries compared with 2010.

${ }^{11}$ Thus, we adopt a somewhat controversial assumption about the substitutability of variables within the group.

Regional Statistics, Vol. 9. No. 1. 2019: 32-53; DOI: 10.15196/RS090107 
The next four tables present the composite indicators respectively, for the EU10 countries:

- $I_{1}$ - smart development,

- $I_{2}$ - sustainable development,

- $I_{3}$ - inclusive development,

- I- socio-economic development.

The tables contain the composite indicator values for both reference groups as well as the rankings derived from these indicators (in the EU28 environment, only the EU10 countries are classified; the remaining countries are omitted from the classification).

For better visualization, the socio-economic development results for the last year of the analysis (2015) are presented on maps. The countries are divided into three groups by the value of their composite indicator $I$ (the borders are mean value $+/-$ standard deviation). Figures 1 and 2 show the results for the EU10 and EU28 environments, respectively.

Figure 1

\section{Socio-economic development calculated for the reference group of the EU10} countries, 2015

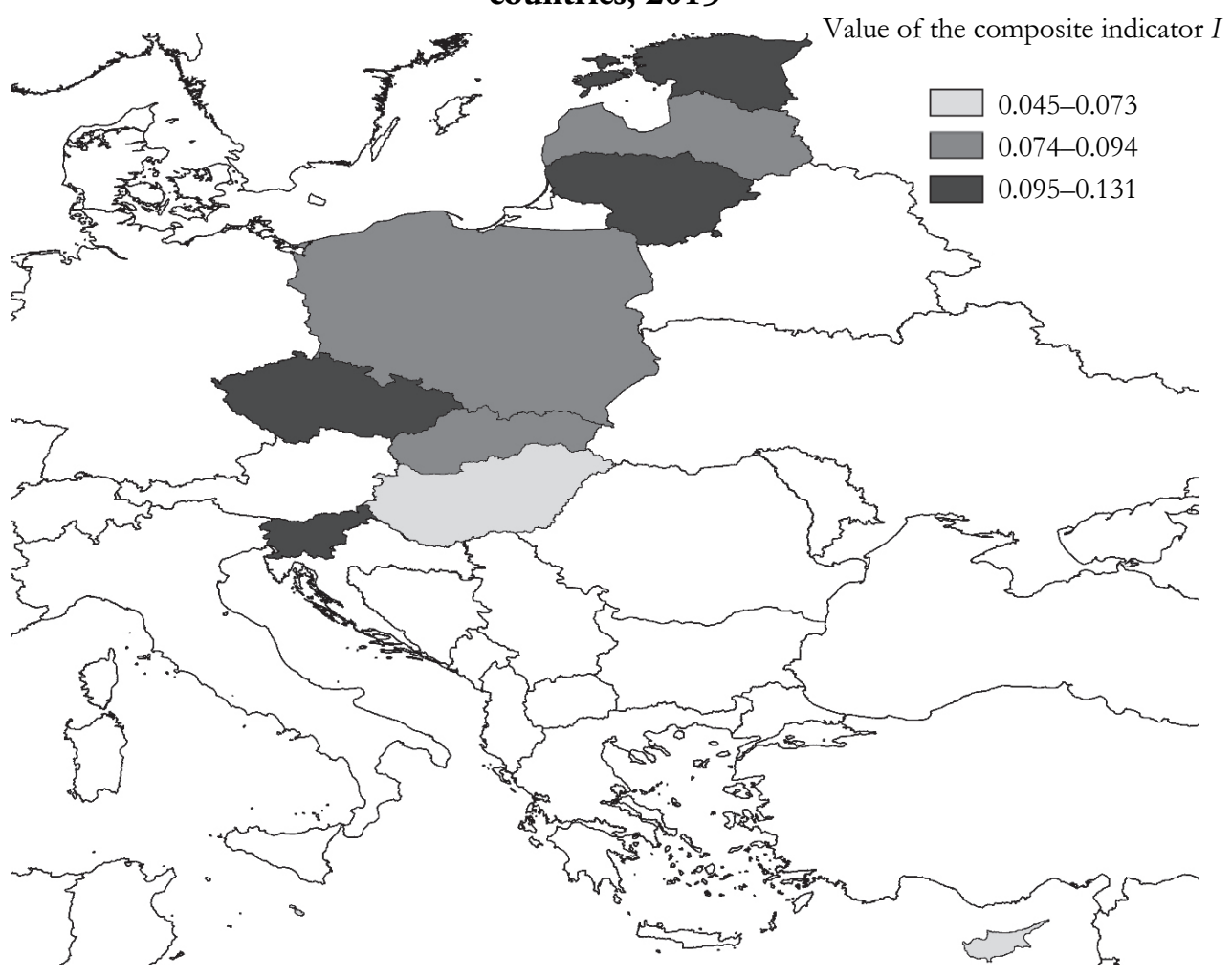


Figure 2

Socio-economic development calculated for the reference group of the EU28 countries, 2015

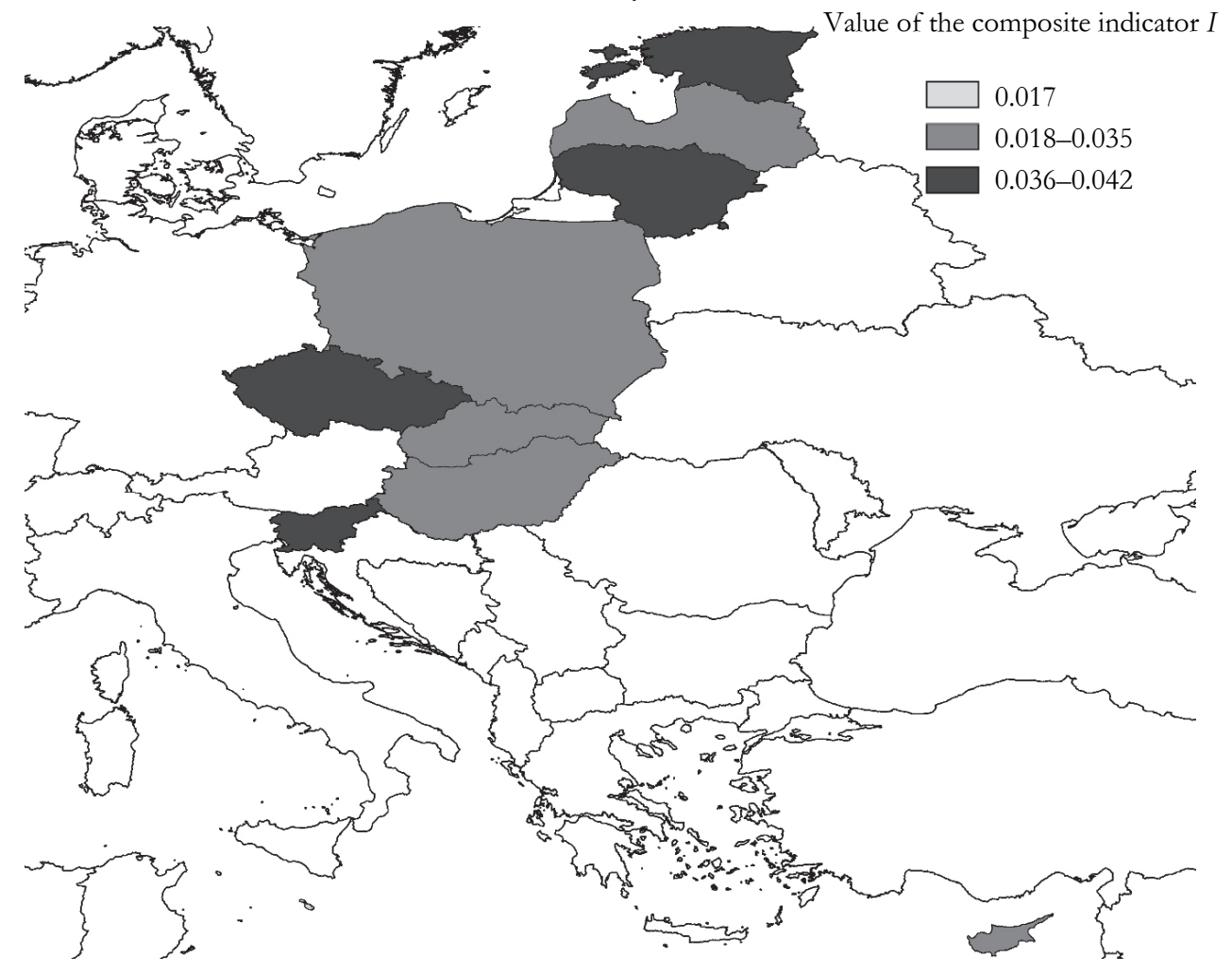

The synthetic analysis results for the remaining 18 EU countries are not presented here because these countries form only the background of the study. However, note that 12 countries show a decrease in the value of the socio-economic development measure $I$ in the extreme years of the study $(2010,2015)$. For comparison, six out of the ten countries that joined the EU in 2004 showed improvement in this measure (compare Appendix Table 5). When all the EU countries are included in the classification (this classification is not presented), the EU10 countries are found to be a weaker group of countries at the time the strategy was introduced (in 2010). The exceptions are Slovenia in the fifth and Estonia in the tenth EU position. The remaining EU10 countries are in the second 10 (six countries) and third 10 (two countries). Half of the EU10 countries show an improvement in ranking after six years. The Czech Republic and Lithuania as well as Slovenia and Estonia are in the top 10 of the classification.

Regional Statistics, Vol. 9. No. 1. 2019: 32-53; DOI: 10.15196/RS090107 


\section{Discussion of empirical results}

The results presented in Section 4 are analysed for similarity of approaches in the two environments. Even a quick analysis shows significantly different results for the two approaches. An obvious example is Cyprus, the first country in Table 5, whose socio-economic-development-based position among the EU10 countries in 2011 and 2012 differs in the two environments. The difference between the two environments is also evident when the countries are divided into groups by the level of development (compare Figure 1 and Figure 2). However, some countries show identical positions in the classifications or group allocations of the two approaches. Descriptive statistics tools are used to examine similarity in general.

For each analysed year and each composite indicator $\left(I_{1}, I_{2}, I_{3}, I\right)$, the EU10 country rankings in the two environments are compared. The similarity of rankings is examined using Spearman's rho and Kendall's tau correlation coefficients. The obtained values are presented in Table 1.

Table 1

Compatibility of the results obtained for the two environments of the analysis

\begin{tabular}{l|l|c|c|c|c|c|c}
\hline Coefficient & Development & 2010 & 2011 & 2012 & 2013 & 2014 & 2015 \\
\hline \multirow{2}{*}{ Spearman's rho } & Smart & 0.988 & 0.976 & 0.952 & 0.976 & 0.891 & 0.927 \\
& Sustainable & 0.988 & 0.988 & 0.964 & 0.952 & 0.988 & 0.976 \\
& Inclusive & 1.000 & 0.988 & 0.988 & 0.964 & 0.830 & 0.855 \\
& Socio-economic & 0.915 & 0.794 & 0.830 & 0.927 & 0.964 & 0.915 \\
\hline \multirow{3}{*}{ Kendall's tau } & Smart & 0.956 & 0.933 & 0.911 & 0.933 & 0.844 & 0.889 \\
& Sustainable & 0.956 & 0.956 & 0.933 & 0.911 & 0.956 & 0.933 \\
& Inclusive & 1.000 & 0.978 & 0.978 & 0.933 & 0.822 & 0.800 \\
& Socio-economic & 0.822 & 0.733 & 0.778 & 0.800 & 0.844 & 0.778
\end{tabular}

Both rankings typically show strong (even full) compliance, but in some cases, the ranking compliance is much smaller. For most of the years, the general composite indicators are the least similar in classification. An interesting situation occurs for the third group (inclusive development); in this case, compatibility decreases over time.

In the next step, we analyse the stability of rankings between 2010 and 2015. Separately for each environment, we examine the compatibility of the rankings obtained for the six years. Kendall's W statistic is used for this purpose. The results are presented in Table 2. 
Table 2

Stability of rankings over time, 2010-2015

\begin{tabular}{c|c|c|c|c}
\hline \multirow{2}{*}{ Environment } & Smart & Sustainable & Inclusive & Socio-economic \\
\cline { 2 - 5 } & \multicolumn{4}{|c|}{ development } \\
\hline EU10 & 0.964 & 0.982 & 0.822 & 0.902 \\
EU28 & 0.941 & 0.985 & 0.894 & 0.935
\end{tabular}

Note: We used Kendall's W statistic.

The rankings of the third group (inclusive development) are the least similar in the two environments. Therefore, the question whether the environments influence the stability of the results over time remained unanswered. For sustainable development, both environments showed similar results; for smart development, the EU10 showed more consistent results; and for inclusive and socio-economic development, the entire EU showed more compatible results.

\section{Example of Poland}

In order to show clearly the differences between the considered approaches, we carry out an in-depth analysis of the research results for Poland. First, we examine the influence of normalization in the two environments on the country's image based on individual indicators, priorities of strategy, and the level of socio-economic development. Then we analyse the study's initial results.

To begin with, the situation of Poland before and after normalization based on individual indicators is compared. The anti-pattern normalization of indicators does not affect the country's ranking, but it can change its 'dynamic image'. For example, the observed country's value of stimulants may increase over time, and then decrease after normalization. This occurs when the other countries' improvement is greater. ${ }^{12}$ The results presented in Appendix Table 1 are examined in this context. The changes in the study's extreme years and the tendency in time are analysed. The raw data, the indicator values after normalization, and Poland's rankings are examined. The results are shown in Table 3.

${ }^{12}$ Such differences would not be visible for the scaling (1) mentioned in Section 2.

Regional Statistics, Vol. 9. No. 1. 2019: 32-53; DOI: 10.15196/RS090107 
Table 3

Impact of normalization in various environments on Poland's dynamic image in terms of particular indicators monitoring the implementation of the Europe 2020 strategy

\begin{tabular}{|c|c|c|c|c|c|c|c|}
\hline \multirow{3}{*}{$\begin{array}{l}\text { Indica- } \\
\text { tor }\end{array}$} & \multicolumn{4}{|c|}{ Growth in 2015 compared with 2010} & \multicolumn{3}{|c|}{ Year-to-year increment } \\
\hline & \multirow[b]{2}{*}{ Raw data } & \multicolumn{2}{|c|}{ Normalized data } & \multirow{2}{*}{$\begin{array}{c}\text { Rank } \\
\text { differ- } \\
\text { ence }\end{array}$} & \multirow[b]{2}{*}{ Raw data } & \multicolumn{2}{|c|}{ Normalized data } \\
\hline & & EU10 & EU28 & & & EU10 & EU28 \\
\hline$x_{1}$ & + & + & + & +1 & $\mathrm{x}$ & $\mathrm{x}$ & $\mathrm{x}$ \\
\hline$x_{2}$ & + & - & + & -1 & $\mathrm{x}$ & $\mathrm{x}$ & $\mathrm{x}$ \\
\hline$x_{3}$ & + & 0 & + & 0 & + & $\mathrm{x}$ & $\mathrm{x}$ \\
\hline$x_{4}$ & + & - & - & 0 & $\mathrm{x}$ & $\mathrm{x}$ & $\mathrm{x}$ \\
\hline$x_{5}$ & + & - & - & +1 & + & $\mathrm{x}$ & $\mathrm{x}$ \\
\hline$x_{6}$ & + & + & + & 0 & + & $\mathrm{x}$ & $\mathrm{x}$ \\
\hline$x_{7}$ & + & - & + & +2 & + & - & + \\
\hline$x_{8}$ & + & + & + & -2 & + & + & + \\
\hline$x_{9}$ & + & + & + & -1 & $\mathrm{x}$ & $\mathrm{x}$ & + \\
\hline$x_{10}$ & 0 & + & + & -1 & $\mathrm{x}$ & $\mathrm{x}$ & $\mathrm{x}$ \\
\hline$x_{11}$ & + & + & + & -3 & $\mathrm{x}$ & + & + \\
\hline
\end{tabular}

Note: + better; - worse; 0 no change; $x$ not determined (i.e. the tendency in time is not permanent).

From a comparison of the results for the study's extreme years, we find no raw indicator value worsening. However, some normalized indicators show a decline (i.e. decrease in the value of stimulants and increase in the value destimulants). We find several examples for this deterioration. Normalized variables $x_{4}$ and $x_{5}$ have worsening values in both environments. Thus, for these indicators, the improvement in extreme years for Poland was not as strong as that for other countries. The normalized values of $x_{2}$ and $x_{7}$ changed for the worse only in the EU10 environment. Thus, the situation (percentage of early leavers from education and training; employment rate of persons aged 20-64) in Poland improves relative to the whole EU, but only smaller improvement can be seen compared with the EU10. An interesting situation is observed for $x_{10}$. The value of the raw indicator did not change in the extreme years, but improved for both environments after normalisation. This means that in this respect, the situation (percentage of people at risk-ofpoverty rate) in other countries is deteriorating.

Some of the described differences (before and after normalization) are reflected in the classification, but not all of them. For example, there is a drop in the ranking for $x_{5}$, so it is not surprising that its value falls after anti-pattern normalization. We can take $x_{10}$ as another example. The position of Poland in the ranking for this indicator improved, so an increase in its normalized value is not a surprise. However, in the

Regional Statistics, Vol. 9. No. 1. 2019: 32-53; DOI: 10.15196/RS090107 
case of $x_{4}$ the deterioration of Poland's situation compared with other countries is not apparent in the classification, but in the fall in the normalized value of this indicator.

A year-by-year comparison of the results (raw data) shows that the situation in Poland is improving for five variables, but after normalization, only two of those variables show improvement in the EU10 environment. The most interesting results are given by $x$, whose raw values are increasing year by year, whereas after normalization, they increase in the EU28 environment but decrease in the EU10 environment. This variable shows especially the utility of normalization with respect to antipattern in the creation of composite indicators. Through application of this normalization, we can consider the different environmental contexts of the study and possibly come to different conclusions.

In the next step, we compare the synthetic results in terms of differences resulting from normalization in various environments. Such differences are found in the classification for some years. For example, the position of Poland in 2014 is identical for both environments only for the second priority (sustainable development). Interestingly, in this year, Poland shows a better position for $I_{1}$ (smart development) and $I_{3}$ (inclusive development) with the whole EU as a background, but generally (socio-economic development) its position is better for a smaller group of countries (EU10).

Then, just as for individual indicators, we analyse the dynamics of the socioeconomic development and examine the composite indicators and ranking positions. The extreme years and year-to-year comparison results are shown in Table 4.

Table 4

\section{Impact of normalization in various environments on the dynamic image of Poland in terms of strategy priorities and the level of socio-economic development}

\begin{tabular}{c|c|c|c|c|c|c|c|c}
\hline \multirow{2}{*}{$\begin{array}{c}\text { Composite } \\
\text { indicator }\end{array}$} & \multicolumn{2}{|c|}{ Growth in 2015 compared with 2010 } & \multicolumn{3}{c}{ Year-to-year increment } \\
\cline { 2 - 9 } & \multicolumn{2}{|c|}{ Value } & \multicolumn{2}{|c|}{ Position } & \multicolumn{2}{|c|}{ Value } & \multicolumn{2}{c}{ Position } \\
\cline { 2 - 8 } & EU10 & EU28 & EU10 & EU28 & EU10 & EU28 & EU10 & EU28 \\
\hline$I_{1}$ & + & + & +2 & 0 & $\mathrm{x}$ & $\mathrm{x}$ & $\mathrm{x}$ & $\mathrm{x}$ \\
$I_{2}$ & - & - & +1 & 0 & $\mathrm{x}$ & $\mathrm{x}$ & $\mathrm{x}$ & 0 \\
$I_{3}$ & + & + & -2 & -2 & $\mathrm{x}$ & + & $\mathrm{x}$ & $\mathrm{x}$ \\
$I$ & + & + & 0 & 0 & $\mathrm{x}$ & $\mathrm{x}$ & $\mathrm{x}$ & 0
\end{tabular}

Note: + better; - worse; 0 no change; $x$ not determined (i.e. the tendency in time was not permanent).

Based on the synthetic analysis, the difference is less clear between the presented approaches than for individual indicators. It is only visible in the classification results when comparing the extreme years of the study, and not the values of 
synthetic measures. For $I_{1}$ and $I_{2}$, the position of Poland improves in the EU10 environment but does not change in the EU28 environment.

\section{Conclusion}

The article presents a new tool for multivariate comparative analysis - a composite indicator based on normalization with respect to anti-pattern. The proposed construction has important advantages. First, it can be adapted to dynamic research such that you do not have to recalculate the results for observations in a new time unit. Second, the analysis environment is significant, that is you can look at objects (countries, regions, etc.) from different perspectives.

An empirical illustration shows the utility of the new tool. The results obtained for different environments are similar, but not identical.

Anti-pattern normalization is particularly useful in dynamic synthetic studies, where the analysis environment is important. The obtained results are relative, that is, they characterize the situation of the object against the background of an established reference group, therefore it is good to confront them with the results obtained with other types of normalization.

Besides the presented construction, normalization with respect to pattern or anti-pattern can be used with other forms of aggregation. The construction in Müller-Frączek (2017) is based on the arithmetic mean, whereas the aggregation in Müller-Frączek (2018) follows Hellwig (1968). Studies are ongoing on the use of anti-pattern normalization in the Adjusted Mazziatto-Pareto Index (MazziottaPareto 2016). This direction will be developed in future research.

\section{Acknowledgement}

I am grateful for the maps courtesy of Géza Tóth.

\section{REFERENCES}

Booysen, F. (2002): An overview and evaluation of composite indices of development Social Indicators Research 59(2): 115-151. https://doi.org/10.1023/A:1016275505152

CASAdio TARABUsi, E.-GuARINI, G. (2013): An unbalance adjustment method for development indicators Social Indicators Research 112(1): 19-45. https://doi.org/10.1007/s11205-012-0070-4

EGRI, Z.-TÁNCZOS, T. (2018): The spatial peculiarities of economic and social convergence in Central and Eastern Europe Regional Statistics 8(1): 49-77. https://doi.org/10.15196/RS080108

FURA, B.-WANG, Q. (2017): The level of socioeconomic development of EU countries and the state of ISO 14001 certification Quality \& Quantity 51(1): 103-119. https://doi.org/10.1007/s11135-015-0297-7

Hellwig, Z. (1968): Zastosowanie metody taksonomicznej do typologicznego podziału krajów ze względu na poziom ich rozwoju i strukturę kwalifikowanych kadr Prz̨eglead Statystyczny 15(4): 307-327.

Regional Statistics, Vol. 9. No. 1. 2019: 32-53; DOI: 10.15196/RS090107 
JajugA, K.-WALESIAK, M. (2000): Standardisation of data set under different measurement scales In: DeCKER, R.- GAuL, W. Classification and Information Processing at the Turn of the Millennium pp. 105-112., Springer, Berlin-Heidelberg.

Klugman, J.-RodríGuez, F.-CHOI, H.-J. (2011): The HDI 2010: new controversies, old critiques The Journal of Economic Inequality 9(2): 249-288. https://doi.org/10.1007/s10888-011-9178-z

KukuŁA, K.-BogoCZ, D. (2014): Zero unitarization method and its application in ranking research in agriculture Economic and Regional Studies 7(3): 5-13.

LiRA, J.-WAGNER, W.-WysockI, F. (2002): Mediana w zagadnieniach porządkowania liniowego obiektów wielocechowych In: PARADYSZ, J. Statystyka regionalna $w$ stu̇̀bie samorzqdu lokalnego i biznesu pp. 87-99. Internetowa Oficyna Wydawnicza, Centrum Statystyki Regionalnej, Poznań.

MAZZiotTA, M.-PARETO, A. (2013): Methods for constructing composite indices: one for all or all for one Rivista Italiana di Economia Demografia e Statistica 67(2): 67-80.

MAZZiotTA, M.-PARETO, A. (2016): On a generalized non-compensatory composite index for measuring socio-economic phenomena Social Indicators Research 127(3): 983-1003. https://doi.org/10.1007/s11205-015-0998-2

Milligan, G.-COOPER, M. (1988): A study of standardization of variables in cluster analysis Journal of Classification 5(2): 181-204. https://doi.org/10.1007/BF01897163

MŁodAK, A. (2006): Multilateral normalizations of diagnostic features Statistics in Transition 7(5): 1125-1139. https://doi.org/10.1007/s00357-011-9088-6

MŁODAK, A. (2014): On the construction of an aggregated measure of the development of interval data Computational Statistics 29(5): 895-929. https://doi.org/10.1007/s00180-013-0469-7

MÜLlER-FrĄCZEK, I. (2017): Propozycja miary syntetycznej Przeglad Statystyczny 64(4): 413-428.

MÜLleR-FrĄCZEK, I. (2018): Dynamic measure of development In: PAPIEŻ, V.-ŚMIECH, S. $12^{\text {th }}$ Professor Aleksander Zelias International Conference on Modelling and Forecasting of Socio-Economic Phenomena. Conference Proceedings pp. 326-334., Foundation of the Cracow University of Economics, Kraków.

MÜLLER-FrĄCZEK, I. (2019): Pattern normalization - a new tool for dynamic comparisons Statistika: Statistics and Economy Journal 99(2): 182-197.

MÜLleR-FrAcZZEK, I.-MuszyŃSKA, J. (2016): Implementation of Europe 2020 Strategy: the taxonomic analysis In: Simberova, I.-Milichovsky, F.-ZiZLAvsky, O. Smart and Efficient Economy: Preparation for the Future Innovative Economy pp. 346-355., University of Technology Faculty of Business and Management, Brno.

Nardo, M.-Saisana, M.-Saltelli, A.-Tarantola, S.-Hoffman, A.-Giovannini, E. (2005): Handbook on Constructing Composite Indicators OECD Publishing, Washington.

SAISANA, M.-SALTELLI, A. (2011): Rankings and Ratings: Instructions for use Hague Journal on the Rule of Law 3(2): 247-268. https://doi.org/10.1017/S1876404511200058

SALteldi, A. (2007): Composite indicators between analysis and advocacy Social Indicators Research 81(1): 65-77. https://doi.org/10.1007/s11205-006-0024-9

STATISTICS POLAND (2018): Europe 2020 indicators. https://stat.gov.pl/en/internationalstatistics/international-comparisons/tables-about-countries-by-subject/europe2020-indicators/

Regional Statistics, Vol. 9. No. 1. 2019: 32-53; DOI: 10.15196/RS090107 
TARANTOLA, S. (2008): European Innovation Scoreboard: strategies to measure country progress over time JRC scientific and Technical Reports EUR - Scientific and Technical Research Reports No. 23526, Brussels.

VALKÓ, G.-FEKETE-FARKAS, M.-KOVÁCS, I. (2017): Indicators for the economic dimension of sustainable agriculture in the European Union Regional Statistics 7(1): 179-196. https://doi.org/10.15196/RS07110

ZELIAŚ, A. (2002): Some notes on the selection of normalization of diagnostic variables Statistics in Transition 5(5): 787-802. 


\section{APPENDIX}

Table 1

Individual indicators and corresponding positions - The example of Poland

\begin{tabular}{|c|c|c|c|c|c|c|c|c|}
\hline \multicolumn{2}{|c|}{ Indicator } & Normalization & 2010 & 2011 & 2012 & 2013 & 2014 & 2015 \\
\hline \multirow{4}{*}{$x_{1}$} & & None & 0.720 & 0.750 & 0.880 & 0.870 & 0.940 & 1.000 \\
\hline & Value & EU10 & 0.050 & 0.041 & 0.056 & 0.053 & 0.063 & 0.071 \\
\hline & & EU28 & 0.009 & 0.009 & 0.013 & 0.014 & 0.016 & 0.016 \\
\hline & Rank & Any & 6 & 6 & 6 & 6 & 6 & 7 \\
\hline \multirow{4}{*}{$x_{2}$} & Value & None & 5.400 & 5.600 & 5.700 & 5.600 & 5.400 & 5.300 \\
\hline & & EU10 & 0.132 & 0.129 & 0.130 & 0.128 & 0.128 & 0.131 \\
\hline & & EU28 & 0.051 & 0.050 & 0.050 & 0.049 & 0.049 & 0.052 \\
\hline & Rank & Any & 4 & 4 & 4 & 3 & 2 & 3 \\
\hline \multirow{4}{*}{$x_{3}$} & & None & 34.800 & 36.500 & 39.100 & 40.500 & 42.100 & 43.400 \\
\hline & Value & EU10 & 0.122 & 0.122 & 0.128 & 0.126 & 0.127 & 0.122 \\
\hline & & EU28 & 0.037 & 0.039 & 0.042 & 0.042 & 0.042 & 0.043 \\
\hline & Rank & Any & 4 & 5 & 5 & 5 & 4 & 4 \\
\hline \multirow{4}{*}{$x_{4}$} & & None & 87.170 & 87.050 & 85.500 & 84.750 & 82.110 & 82.760 \\
\hline & Value & EU10 & 0.095 & 0.094 & 0.093 & 0.088 & 0.091 & 0.087 \\
\hline & & EU28 & 0.037 & 0.036 & 0.036 & 0.035 & 0.035 & 0.034 \\
\hline & Rank & Any & 7 & 7 & 7 & 7 & 7 & 7 \\
\hline \multirow{4}{*}{$x_{5}$} & & None & 9.300 & 10.300 & 10.900 & 11.400 & 11.500 & 11.800 \\
\hline & Value & EU10 & 0.062 & 0.063 & 0.060 & 0.057 & 0.052 & 0.051 \\
\hline & & EU28 & 0.020 & 0.021 & 0.020 & 0.019 & 0.017 & 0.016 \\
\hline & Rank & Any & 7 & 7 & 7 & 7 & 8 & 8 \\
\hline \multirow{4}{*}{$x_{6}$} & & None & 278.300 & 265.300 & 252.800 & 250.300 & 233.300 & 227.300 \\
\hline & Value & EU10 & 0.083 & 0.082 & 0.084 & 0.086 & 0.090 & 0.087 \\
\hline & & EU28 & 0.024 & 0.026 & 0.027 & 0.025 & 0.027 & 0.028 \\
\hline & Rank & Any & 8 & 8 & 8 & 8 & 8 & 8 \\
\hline \multirow{4}{*}{$x_{7}$} & & None & 64.300 & 64.500 & 64.700 & 64.900 & 66.500 & 67.800 \\
\hline & Value & EU10 & 0.072 & 0.064 & 0.054 & 0.040 & 0.019 & 0.003 \\
\hline & & EU28 & 0.019 & 0.021 & 0.027 & 0.028 & 0.030 & 0.031 \\
\hline & Rank & Any & 6 & 8 & 8 & 8 & 8 & 8 \\
\hline \multirow{4}{*}{$x_{8}$} & & None & 27.800 & 27.200 & 26.700 & 25.800 & 24.700 & 23.400 \\
\hline & Value & EU10 & 0.079 & 0.090 & 0.091 & 0.099 & 0.100 & 0.107 \\
\hline & & EU28 & 0.031 & 0.033 & 0.034 & 0.035 & 0.036 & 0.038 \\
\hline & Rank & Any & 7 & 7 & 6 & 6 & 5 & 5 \\
\hline \multirow{4}{*}{$x_{9}$} & & None & 7.300 & 6.900 & 6.900 & 7.200 & 7.300 & 6.900 \\
\hline & Value & EU10 & 0.132 & 0.158 & 0.145 & 0.138 & 0.141 & 0.144 \\
\hline & & EU28 & 0.042 & 0.045 & 0.045 & 0.046 & 0.048 & 0.050 \\
\hline & Rank & Any & 4 & 3 & 3 & 2 & 2 & 3 \\
\hline \multirow{4}{*}{$x_{10}$} & & None & 17.600 & 17.700 & 17.100 & 17.300 & 17.000 & 17.600 \\
\hline & Value & EU10 & 0.058 & 0.040 & 0.054 & 0.068 & 0.085 & 0.085 \\
\hline & & EU28 & 0.025 & 0.027 & 0.031 & 0.031 & 0.035 & 0.033 \\
\hline & Rank & Any & 8 & 8 & 7 & 7 & 7 & 7 \\
\hline \multirow{4}{*}{$x_{11}$} & & None & 14.200 & 13.000 & 13.500 & 11.900 & 10.400 & 8.100 \\
\hline & Value & EU10 & 0.094 & 0.104 & 0.106 & 0.112 & 0.115 & 0.129 \\
\hline & & EU28 & 0.032 & 0.033 & 0.034 & 0.035 & 0.036 & 0.038 \\
\hline & Rank & Any & 7 & 7 & 6 & 6 & 6 & 4 \\
\hline
\end{tabular}

Note: Here and hereinafter, EU10 - countries that joined the EU in 2004; EU28 - all the EU countries. The indicator values are presented in three versions: before normalization, after anti-pattern normalization in the EU10 environment, and after anti-pattern normalization in the EU28 environment.

Source: Here and hereinafter, own calculation based on data from Statistics Poland.

Regional Statistics, Vol. 9. No. 1. 2019: 32-53; DOI: 10.15196/RS090107 
Table 2

The composite indicator of smart development

\begin{tabular}{|c|c|c|c|c|c|c|c|c|}
\hline Country & $\begin{array}{l}\text { Composite } \\
\text { indicator } I_{1}\end{array}$ & Environment & 2010 & 2011 & 2012 & 2013 & 2014 & 2015 \\
\hline \multirow{4}{*}{ Cyprus } & \multirow{2}{*}{ Value } & EU10 & 0.097 & 0.099 & 0.100 & 0.096 & 0.109 & 0.114 \\
\hline & & EU28 & 0.032 & 0.033 & 0.034 & 0.033 & 0.038 & 0.040 \\
\hline & \multirow{2}{*}{ Rank } & EU10 & 6 & 4 & 6 & 6 & 5 & 4 \\
\hline & & EU28 & 5 & 4 & 5 & 6 & 3 & 3 \\
\hline \multirow{4}{*}{ Czech Republic } & \multirow{2}{*}{ Value } & EU10 & 0.100 & 0.099 & 0.106 & 0.110 & 0.119 & 0.113 \\
\hline & & EU28 & 0.029 & 0.032 & 0.034 & 0.034 & 0.035 & 0.035 \\
\hline & \multirow{2}{*}{ Rank } & EU10 & 5 & 5 & 4 & 4 & 3 & 5 \\
\hline & & EU28 & 6 & 6 & 6 & 5 & 5 & 6 \\
\hline \multirow{4}{*}{ Estonia } & \multirow{2}{*}{ Value } & EU10 & 0.156 & 0.170 & 0.146 & 0.136 & 0.115 & 0.115 \\
\hline & & EU28 & 0.042 & 0.048 & 0.044 & 0.041 & 0.035 & 0.035 \\
\hline & \multirow{2}{*}{ Rank } & EU10 & 2 & 2 & 2 & 3 & 4 & 3 \\
\hline & & EU28 & 2 & 2 & 2 & 3 & 6 & 5 \\
\hline \multirow{4}{*}{ Hungary } & \multirow{2}{*}{ Value } & EU10 & 0.090 & 0.078 & 0.078 & 0.085 & 0.087 & 0.082 \\
\hline & & EU28 & 0.026 & 0.026 & 0.026 & 0.028 & 0.028 & 0.026 \\
\hline & \multirow{2}{*}{ Rank } & EU10 & 7 & 7 & 7 & 7 & 7 & 7 \\
\hline & & EU28 & 7 & 8 & 8 & 8 & 8 & 7 \\
\hline \multirow{4}{*}{ Latvia } & \multirow{2}{*}{ Value } & EU10 & 0.070 & 0.078 & 0.076 & 0.079 & 0.079 & 0.072 \\
\hline & & EU28 & 0.024 & 0.027 & 0.027 & 0.029 & 0.028 & 0.026 \\
\hline & \multirow{2}{*}{ Rank } & EU10 & 8 & 8 & 8 & 8 & 8 & 9 \\
\hline & & EU28 & 8 & 7 & 7 & 7 & 7 & 8 \\
\hline \multirow{4}{*}{ Lithuania } & \multirow{2}{*}{ Value } & EU10 & 0.124 & 0.128 & 0.129 & 0.136 & 0.140 & 0.146 \\
\hline & & EU28 & 0.038 & 0.040 & 0.042 & 0.043 & 0.045 & 0.048 \\
\hline & \multirow{2}{*}{ Rank } & EU10 & 3 & 3 & 3 & 2 & 2 & 2 \\
\hline & & EU28 & 3 & 3 & 3 & 2 & 2 & 2 \\
\hline \multirow{4}{*}{ Malta } & \multirow{2}{*}{ Value } & EU10 & 0.015 & 0.011 & 0.020 & 0.013 & 0.010 & 0.013 \\
\hline & & EU28 & 0.008 & 0.008 & 0.010 & 0.009 & 0.007 & 0.005 \\
\hline & \multirow{2}{*}{ Rank } & EU10 & 10 & 10 & 10 & 10 & 10 & 10 \\
\hline & & EU28 & 10 & 10 & 10 & 10 & 10 & 10 \\
\hline \multirow{4}{*}{ Poland } & \multirow{2}{*}{ Value } & EU10 & 0.101 & 0.098 & 0.105 & 0.103 & 0.106 & 0.108 \\
\hline & & EU28 & 0.032 & 0.033 & 0.035 & 0.035 & 0.036 & 0.037 \\
\hline & \multirow{2}{*}{ Rank } & EU10 & 4 & 6 & 5 & 5 & 6 & 6 \\
\hline & & EU28 & 4 & 5 & 4 & 4 & 4 & 4 \\
\hline & & EU10 & 0.061 & 0.054 & 0.060 & 0.059 & 0.058 & 0.073 \\
\hline & $V$ alue & EU28 & 0.022 & 0.021 & 0.022 & 0.023 & 0.022 & 0.025 \\
\hline Slovakia & Bon & EU10 & 9 & 9 & 9 & 9 & 9 & 8 \\
\hline & Kank & EU28 & 9 & 9 & 9 & 9 & 9 & 9 \\
\hline & & EU10 & 0.185 & 0.185 & 0.181 & 0.184 & 0.176 & 0.164 \\
\hline Sho & $\nabla$ alue & EU28 & 0.047 & 0.053 & 0.053 & 0.053 & 0.050 & 0.050 \\
\hline Slovenia & & EU10 & 1 & 1 & 1 & 1 & 1 & 1 \\
\hline & Ra & EU28 & 1 & 1 & 1 & 1 & 1 & 1 \\
\hline
\end{tabular}

Note: In the EU28 environment, only the EU10 countries are classified; the remaining EU countries are omitted from the classification.

Regional Statistics, Vol. 9. No. 1. 2019: 32-53; DOI: 10.15196/RS090107 
Dynamic measurement of complex phenomena in assessing the Europe 2020 strategy effects

Table 3

The composite indicator of sustainable development

\begin{tabular}{|c|c|c|c|c|c|c|c|c|}
\hline Country & $\begin{array}{l}\text { Composite } \\
\text { indicator } I_{2}\end{array}$ & Environment & 2010 & 2011 & 2012 & 2013 & 2014 & 2015 \\
\hline \multirow{4}{*}{ Cyprus } & \multirow{2}{*}{ Value } & EU10 & 0.067 & 0.065 & 0.066 & 0.064 & 0.061 & 0.062 \\
\hline & & EU28 & 0.018 & 0.017 & 0.017 & 0.018 & 0.017 & 0.017 \\
\hline & \multirow{2}{*}{ Rank } & EU10 & 10 & 10 & 9 & 9 & 10 & 10 \\
\hline & & EU28 & 10 & 10 & 9 & 9 & 10 & 10 \\
\hline \multirow{4}{*}{ Czech Republic } & \multirow{2}{*}{ Value } & EU10 & 0.087 & 0.087 & 0.087 & 0.088 & 0.090 & 0.087 \\
\hline & & EU28 & 0.030 & 0.031 & 0.031 & 0.031 & 0.032 & 0.031 \\
\hline & \multirow{2}{*}{ Rank } & EU10 & 7 & 7 & 7 & 7 & 7 & 7 \\
\hline & & EU28 & 7 & 7 & 7 & 7 & 7 & 7 \\
\hline \multirow{4}{*}{ Estonia } & \multirow{2}{*}{ Value } & EU10 & 0.105 & 0.105 & 0.105 & 0.100 & 0.100 & 0.106 \\
\hline & & EU28 & 0.039 & 0.041 & 0.041 & 0.037 & 0.037 & 0.041 \\
\hline & \multirow{2}{*}{ Rank } & EU10 & 4 & 4 & 4 & 5 & 4 & 4 \\
\hline & & EU28 & 3 & 3 & 3 & 3 & 3 & 3 \\
\hline \multirow{4}{*}{ Hungary } & \multirow{2}{*}{ Value } & EU10 & 0.099 & 0.100 & 0.104 & 0.106 & 0.099 & 0.091 \\
\hline & & EU28 & 0.034 & 0.035 & 0.036 & 0.036 & 0.033 & 0.032 \\
\hline & \multirow{2}{*}{ Rank } & EU10 & 5 & 5 & 5 & 4 & 5 & 6 \\
\hline & & EU28 & 5 & 5 & 4 & 4 & 5 & 6 \\
\hline \multirow{4}{*}{ Latvia } & \multirow{2}{*}{ Value } & EU10 & 0.153 & 0.163 & 0.165 & 0.169 & 0.170 & 0.163 \\
\hline & & EU28 & 0.051 & 0.055 & 0.056 & 0.057 & 0.056 & 0.055 \\
\hline & \multirow{2}{*}{ Rank } & EU10 & 1 & 1 & 1 & 1 & 1 & 1 \\
\hline & & EU28 & 1 & 1 & 1 & 1 & 1 & 1 \\
\hline \multirow{4}{*}{ Lithuania } & \multirow{2}{*}{ Value } & EU10 & 0.131 & 0.128 & 0.130 & 0.136 & 0.135 & 0.134 \\
\hline & & EU28 & 0.044 & 0.044 & 0.044 & 0.046 & 0.045 & 0.046 \\
\hline & \multirow{2}{*}{ Rank } & EU10 & 2 & 2 & 2 & 2 & 2 & 2 \\
\hline & & EU28 & 2 & 2 & 2 & 2 & 2 & 2 \\
\hline \multirow{4}{*}{ Malta } & \multirow{2}{*}{ Value } & EU10 & 0.070 & 0.067 & 0.061 & 0.061 & 0.063 & 0.081 \\
\hline & & EU28 & 0.020 & 0.018 & 0.016 & 0.018 & 0.018 & 0.023 \\
\hline & \multirow{2}{*}{ Rank } & EU10 & 9 & 9 & 10 & 10 & 9 & 8 \\
\hline & & EU28 & 9 & 9 & 10 & 10 & 9 & 9 \\
\hline \multirow{4}{*}{ Poland } & \multirow{2}{*}{ Value } & EU10 & 0.080 & 0.080 & 0.079 & 0.077 & 0.078 & 0.075 \\
\hline & & EU28 & 0.027 & 0.028 & 0.027 & 0.026 & 0.026 & 0.026 \\
\hline & \multirow{2}{*}{ Rank } & EU10 & 8 & 8 & 8 & 8 & 8 & 9 \\
\hline & & EU28 & 8 & 8 & 8 & 8 & 8 & 8 \\
\hline & Valuc & EU10 & 0.093 & 0.094 & 0.095 & 0.091 & 0.094 & 0.093 \\
\hline Slovakia & & EU28 & 0.032 & 0.033 & 0.033 & 0.032 & 0.032 & 0.033 \\
\hline & $\mathrm{R}$ & EU10 & 6 & 6 & 6 & 6 & 6 & 5 \\
\hline & Kan & EU28 & 6 & 6 & 6 & 6 & 6 & 5 \\
\hline & Value & EU10 & 0.115 & 0.111 & 0.109 & 0.107 & 0.110 & 0.108 \\
\hline Sloveni & & EU28 & 0.036 & 0.035 & 0.035 & 0.034 & 0.035 & 0.035 \\
\hline Slovenia & & EU10 & 3 & 3 & 3 & 3 & 3 & 3 \\
\hline & Kat & EU28 & 4 & 4 & 5 & 5 & 4 & 4 \\
\hline
\end{tabular}

Note: In the EU28 environment, only the EU10 countries are classified; the remaining EU countries are omitted from the classification.

Regional Statistics, Vol. 9. No. 1. 2019: 32-53; DOI: 10.15196/RS090107 
Table 4

The composite indicator of inclusive development

\begin{tabular}{|c|c|c|c|c|c|c|c|c|}
\hline Country & $\begin{array}{l}\text { Composite } \\
\text { indicator } I_{3}\end{array}$ & Environment & 2010 & 2011 & 2012 & 2013 & 2014 & 2015 \\
\hline \multirow{4}{*}{ Cyprus } & \multirow{2}{*}{ Value } & EU10 & 0.150 & 0.150 & 0.120 & 0.096 & 0.081 & 0.038 \\
\hline & & EU28 & 0.045 & 0.045 & 0.040 & 0.036 & 0.035 & 0.031 \\
\hline & \multirow{2}{*}{ Rank } & EU10 & 3 & 2 & 4 & 6 & 8 & 10 \\
\hline & & EU28 & 3 & 2 & 4 & 6 & 7 & 8 \\
\hline \multirow{4}{*}{ Czech Republic } & \multirow{2}{*}{ Value } & EU10 & 0.173 & 0.179 & 0.186 & 0.192 & 0.191 & 0.202 \\
\hline & & EU28 & 0.052 & 0.052 & 0.051 & 0.053 & 0.052 & 0.053 \\
\hline & \multirow{2}{*}{ Rank } & EU10 & 1 & 1 & 1 & 1 & 1 & 1 \\
\hline & & EU28 & 1 & 1 & 1 & 1 & 1 & 1 \\
\hline \multirow{4}{*}{ Estonia } & \multirow{2}{*}{ Value } & EU10 & 0.110 & 0.105 & 0.118 & 0.127 & 0.126 & 0.147 \\
\hline & & EU28 & 0.036 & 0.038 & 0.039 & 0.039 & 0.037 & 0.040 \\
\hline & \multirow{2}{*}{ Rank } & EU10 & 5 & 5 & 5 & 3 & 2 & 2 \\
\hline & & EU28 & 5 & 5 & 5 & 4 & 5 & 4 \\
\hline \multirow{4}{*}{ Hungary } & \multirow{2}{*}{ Value } & EU10 & 0.055 & 0.048 & 0.030 & 0.024 & 0.031 & 0.053 \\
\hline & & EU28 & 0.028 & 0.026 & 0.027 & 0.027 & 0.027 & 0.033 \\
\hline & \multirow{2}{*}{ Rank } & EU10 & 8 & 8 & 10 & 10 & 10 & 9 \\
\hline & & EU28 & 8 & 9 & 9 & 10 & 9 & 7 \\
\hline \multirow{4}{*}{ Latvia } & \multirow{2}{*}{ Value } & EU10 & 0.014 & 0.021 & 0.032 & 0.054 & 0.057 & 0.062 \\
\hline & & EU28 & 0.017 & 0.021 & 0.026 & 0.028 & 0.027 & 0.030 \\
\hline & \multirow{2}{*}{ Rank } & EU10 & 10 & 10 & 9 & 9 & 9 & 8 \\
\hline & & EU28 & 10 & 10 & 10 & 9 & 10 & 10 \\
\hline \multirow{4}{*}{ Lithuania } & \multirow{2}{*}{ Value } & EU10 & 0.048 & 0.044 & 0.054 & 0.066 & 0.098 & 0.069 \\
\hline & & EU28 & 0.022 & 0.026 & 0.029 & 0.029 & 0.034 & 0.030 \\
\hline & \multirow{2}{*}{ Rank } & EU10 & 9 & 9 & 8 & 8 & 5 & 7 \\
\hline & & EU28 & 9 & 8 & 8 & 8 & 8 & 9 \\
\hline \multirow{4}{*}{ Malta } & \multirow{2}{*}{ Value } & EU10 & 0.092 & 0.097 & 0.100 & 0.097 & 0.085 & 0.085 \\
\hline & & EU28 & 0.031 & 0.034 & 0.036 & 0.037 & 0.037 & 0.038 \\
\hline & \multirow{2}{*}{ Rank } & EU10 & 6 & 6 & 6 & 5 & 7 & 6 \\
\hline & & EU28 & 6 & 6 & 6 & 5 & 6 & 6 \\
\hline \multirow{4}{*}{ Poland } & \multirow{2}{*}{ Value } & EU10 & 0.087 & 0.091 & 0.090 & 0.091 & 0.092 & 0.094 \\
\hline & & EU28 & 0.030 & 0.032 & 0.034 & 0.035 & 0.037 & 0.038 \\
\hline & \multirow{2}{*}{ Rank } & EU10 & 7 & 7 & 7 & 7 & 6 & 5 \\
\hline & & EU28 & 7 & 7 & 7 & 7 & 4 & 5 \\
\hline & Valuc & EU10 & 0.119 & 0.125 & 0.127 & 0.124 & 0.121 & 0.122 \\
\hline Slovakia & & EU28 & 0.040 & 0.040 & 0.041 & 0.042 & 0.044 & 0.044 \\
\hline & $R_{2}>$ & EU10 & 4 & 4 & 3 & 4 & 3 & 4 \\
\hline & Kan & EU28 & 4 & 4 & 3 & 2 & 2 & 2 \\
\hline & Value & EU10 & 0.151 & 0.140 & 0.144 & 0.128 & 0.118 & 0.128 \\
\hline Slovenia & & EU28 & 0.046 & 0.043 & 0.043 & 0.042 & 0.042 & 0.043 \\
\hline & & EU10 & 2 & 3 & 2 & 2 & 4 & 3 \\
\hline & Kat & EU28 & 2 & 3 & 2 & 3 & 3 & 3 \\
\hline
\end{tabular}

Note: In the EU28 environment, only the EU10 countries are classified; the remaining EU countries are omitted from the classification. 
Dynamic measurement of complex phenomena in assessing the Europe 2020 strategy effects

Table 5

The composite indicator of socio-economic development

\begin{tabular}{|c|c|c|c|c|c|c|c|c|}
\hline Country & $\begin{array}{l}\text { Composite } \\
\text { indicator } I\end{array}$ & Environment & 2010 & 2011 & 2012 & 2013 & 2014 & 2015 \\
\hline \multirow{4}{*}{ Cyprus } & \multirow{2}{*}{ Value } & EU10 & 0.099 & 0.099 & 0.093 & 0.084 & 0.081 & 0.065 \\
\hline & & EU28 & 0.029 & 0.029 & 0.029 & 0.028 & 0.028 & 0.028 \\
\hline & \multirow{2}{*}{ Rank } & EU10 & 4 & 4 & 5 & 8 & 8 & 9 \\
\hline & & EU28 & 7 & 8 & 9 & 9 & 9 & 9 \\
\hline \multirow{4}{*}{ Czech Republic } & \multirow{2}{*}{ Value } & EU10 & 0.115 & 0.115 & 0.120 & 0.123 & 0.127 & 0.126 \\
\hline & & EU28 & 0.036 & 0.037 & 0.038 & 0.038 & 0.039 & 0.039 \\
\hline & \multirow{2}{*}{ Rank } & EU10 & 3 & 3 & 3 & 2 & 2 & 2 \\
\hline & & EU28 & 3 & 3 & 4 & 4 & 3 & 3 \\
\hline \multirow{4}{*}{ Estonia } & \multirow{2}{*}{ Value } & EU10 & 0.122 & 0.124 & 0.121 & 0.120 & 0.113 & 0.121 \\
\hline & & EU28 & 0.039 & 0.042 & 0.041 & 0.039 & 0.036 & 0.039 \\
\hline & \multirow{2}{*}{ Rank } & EU10 & 2 & 2 & 2 & 3 & 4 & 3 \\
\hline & & EU28 & 2 & 2 & 2 & 3 & 4 & 4 \\
\hline \multirow{4}{*}{ Hungary } & \multirow{2}{*}{ Value } & EU10 & 0.079 & 0.072 & 0.062 & 0.060 & 0.065 & 0.073 \\
\hline & & EU28 & 0.029 & 0.029 & 0.029 & 0.030 & 0.029 & 0.030 \\
\hline & \multirow{2}{*}{ Rank } & EU10 & 8 & 8 & 9 & 9 & 9 & 8 \\
\hline & & EU28 & 8 & 9 & 8 & 8 & 8 & 8 \\
\hline \multirow{4}{*}{ Latvia } & \multirow{2}{*}{ Value } & EU10 & 0.054 & 0.064 & 0.074 & 0.090 & 0.091 & 0.090 \\
\hline & & EU28 & 0.028 & 0.031 & 0.034 & 0.036 & 0.035 & 0.035 \\
\hline & \multirow{2}{*}{ Rank } & EU10 & 9 & 9 & 8 & 6 & 6 & 7 \\
\hline & & EU28 & 9 & 5 & 5 & 5 & 5 & 5 \\
\hline \multirow{4}{*}{ Lithuania } & \multirow{2}{*}{ Value } & EU10 & 0.092 & 0.090 & 0.097 & 0.107 & 0.123 & 0.111 \\
\hline & & EU28 & 0.033 & 0.036 & 0.038 & 0.039 & 0.041 & 0.041 \\
\hline & \multirow{2}{*}{ Rank } & EU10 & 5 & 5 & 4 & 4 & 3 & 4 \\
\hline & & EU28 & 4 & 4 & 3 & 2 & 2 & 2 \\
\hline \multirow{4}{*}{ Malta } & \multirow{2}{*}{ Value } & EU10 & 0.045 & 0.041 & 0.050 & 0.043 & 0.038 & 0.045 \\
\hline & & EU28 & 0.017 & 0.017 & 0.018 & 0.018 & 0.017 & 0.017 \\
\hline & \multirow{2}{*}{ Rank } & EU10 & 10 & 10 & 10 & 10 & 10 & 10 \\
\hline & & EU28 & 10 & 10 & 10 & 10 & 10 & 10 \\
\hline \multirow{4}{*}{ Poland } & \multirow{2}{*}{ Value } & EU10 & 0.089 & 0.089 & 0.091 & 0.090 & 0.091 & 0.091 \\
\hline & & EU28 & 0.030 & 0.031 & 0.032 & 0.032 & 0.033 & 0.033 \\
\hline & \multirow{2}{*}{ Rank } & EU10 & 6 & 6 & 6 & 5 & 5 & 6 \\
\hline & & EU28 & 6 & 6 & 6 & 6 & 6 & 6 \\
\hline & Valuc & EU10 & 0.088 & 0.086 & 0.090 & 0.087 & 0.087 & 0.094 \\
\hline Slovakia & Value & EU28 & 0.030 & 0.030 & 0.031 & 0.031 & 0.032 & 0.033 \\
\hline & $R_{2}>$ & EU10 & 7 & 7 & 7 & 7 & 7 & 5 \\
\hline & Kan & EU28 & 5 & 7 & 7 & 7 & 7 & 7 \\
\hline & Value & EU10 & 0.148 & 0.142 & 0.141 & 0.136 & 0.132 & 0.131 \\
\hline Slovenia & & EU28 & 0.043 & 0.043 & 0.043 & 0.042 & 0.042 & 0.042 \\
\hline & & EU10 & 1 & 1 & 1 & 1 & 1 & 1 \\
\hline & Kat & EU28 & 1 & 1 & 1 & 1 & 1 & 1 \\
\hline
\end{tabular}

Note: In the EU28 environment, only the EU10 countries are classified; the remaining EU countries are omitted from the classification.

Regional Statistics, Vol. 9. No. 1. 2019: 32-53; DOI: 10.15196/RS090107 